\title{
Darkening Agent for Polyester Fabric
}

\author{
Chengbing Yu*, Yilin Lu and Fangfang Wu \\ School of Materials Science and Engineering, Shanghai University, Shanghai, China
}

*Corresponding author: Chengbing Yu, School of Materials Science and Engineering, Shanghai University, Shanghai 201800, P.R. China.

Received Date: October 24, 2019

Published Date: October 29, 2019

\begin{abstract}
Energy saving, emission reduction and cost decrease are always necessary in dyeing industry, and darkening agent can suit this trend. In this paper, a brief review is also presented about darkening agents for dyed polyester fabric, then the darkening agent emulsified with cationic organic fluorosilicone resin is introduced. The interaction model of the darkening agent and the fiber was analyzed, and the ammonia value of the deepening resin has a great influence on the softness and the finishing durability for polyester fabric.
\end{abstract}

Keywords: Darkening agent; Resin; Finishing; Polyester fabric; Interaction model

\section{Introduction}

Without increasing the amount of dye, the fabric can be dyed deeply, which can result in saving dye, decreasing cost, and reducing the amount of the colored effluent in dyeing. Many researchers have done much research in this field and had many achievements $[1,2]$. The method of fabric deepening can be mainly summarized into three types, the first one is physical or chemical treatment of the fiber to roughen the surface of the textile, reducing the surface reflection of light, which the absorption of the dye can be increased and the apparent depth of the dyed fabric can be improved [3]. The second method is to improve the dyeing fixation rate of the fabric, including graft modification, fiber surface modification, dyeing auxiliary and suitable dyeing process, etc. [4-7] The third approach is to use a finishing with darkening agent, reducing the refractive index of the surface of the dyed fabric, thereby obtaining a dark color effect [8]. Among them, the dyed fabric is treated using a finishing with darkening agent with a low refractive index, and the film on the surface of the fiber is formed to reduce the amount of reflected light so as to achieve a visual shade darkening effect, which is a conventional method used in the dyeing and finishing process of textiles [9].

\section{Darkening Agent}

To obtain a darkening agent with excellent shade darkening effect, a lot of research and exploration have been conducted, and many types of darkening agents have been developed [10-
13]. For low reflectivity, darkening agents based on organosilicon resin are the most conventional one, while the others based on organic fluorine resin have the lower refractive index, but they are expensive and strong hydrophobicity of the finished fabrics [14,15]. The darkening agents based on polyacrylic resin or modified polyacrylic resin have good shade darkening effect, but the finished fabrics are hard, which cannot meet practical wearing needs [16]. Although the darkening agents based on organosilicon are the most commonly used, which can improve the hand feeling of the fabric [17], but their shade darkening effect still needs to be further improved to lower their refractive index. In addition, darkening agents often have many problems in practical use, such as "floating oil" phenomenon.

\section{Cationic Organic Fluorosilicone Resin}

The darkening agent emulsified with cationic organic fluorosilicone resin has excellent overall performance, whose molecular structure is illustrated as [18].

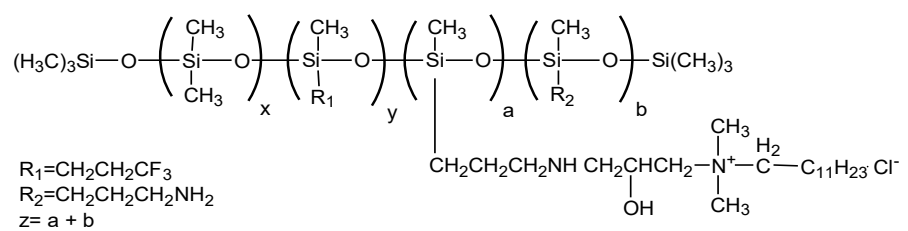

It is a typical darkening agent for polyester fabric. Compared with other darkening agent in the market, it has many 
outstanding and substantial features as follows. Firstly, the raw materials used are easy to obtain and it is easy to prepare. Organic fluorosilicone was synthesized directly by bis-aminotype silane coupling agent with octamethylcyclotetrasiloxane and trifluoropropylmethylcyclotrisiloxane with a traditional bulk polymerization reaction, instead of using the linear octamethylcyclotetrasiloxane and the linear trifluoropropylmethylcyclotrisiloxane [19,20]. Secondly, the resin containing quaternary ammonium salt can be easily emulsified with water after the emulsifier is added [21], the obtained emulsion has smaller particle size and better stability and does not occur "floating oil" phenomenon. The resin in the emulsion can be easily combined with the fiber surface due to charge attraction [22]. Thirdly, the darkening agent with the resin can be used alone or in combination, the darkening effect is obvious, and the feeling and style of the textile after finishing are not only unchanged, but also improved a little, especially for polyester fabrics [23-25].

\section{Interaction Model of Darkening Agent and Polyester Fiber}

When the fabric is treated with the finishing agent emulsified with amino silicone, the resin is uniformly distributed to form a monomolecular layer-aligned film on the surface of the fiber [26], the silicon methyl group extends toward the outside, and the silicon-oxygen dipole bond and the polar amino group are directed to the inside of fiber interface $[27,28]$. The ammonia value of the finishing agent has a great influence on the morphological structure of siloxane chain during film formation [29]. The siloxane chain between two amino hydrocarbon groups forms a free ring shape, which is easy to move and bend, the result is that the friction coefficient between the fibers can be effectively reduced, and the fabric after finishing has soft and smooth feeling [30-32]. However, polyester fiber with dense structure, smooth surface, fewer surface polar groups and strong hydrophobicity is completely different from cotton fiber [33]. Polyester fiber has less polar groups on the surface, the ammonia value of finishing agent has less significant effect than cotton fiber, but still has some influence, the finishing agent with lower ammonia value was used to achieve a good finishing effect. The film formation mechanism of the resin on the surface of polyester fiber is similar to that of cotton fiber [34]. The amino silicone has weaker interaction with polyester fiber [35]. The partial polar side chains of the resin are randomly distributed in the upper layer of polysiloxane, and the adjacent quaternary ammonium salt groups electrostatically repel each other. The polysiloxane segment has a helical structure, so the ammonia value of the resin affects the conformation of the polysiloxane chain on the surface of the fiber [36,37]. Compared with conventional amino silicone, the organosilicon with quaternary ammonium salt groups has stronger interaction with negatively-charged polyester fiber on the surface, which can improve the adhesion and reduce the yellowing [38,39].Suitable length of polysiloxane chains is important to facilitate the formation of uniform film of the resin on the surface of the polyester fiber, and can bend, rotate and slide freely, imparting the softness performance of the fabric [40]. If the ammonia value is too high, the length of the polysiloxane segment is too short, and the main chain cannot move freely, which does not give the fabric a soft feeling. On the contrary, If the ammonia value is too low, the length of the polysiloxane segment is too long to form a non-uniform film of the resin on the surface of the polyester fiber, which also reduces the softness.

\section{Conclusion}

A brief review is presented about darkening agents for dyed polyester fabric. The darkening agent emulsified with cationic organic fluorosilicone resin has excellent overall performance, especially used for polyester fabric. After analyzing the interaction model of the darkening agent and the fiber, it was drawn that the ammonia value of the deepening resin has a great influence on the softness and the finishing durability for polyester fabric.

\section{Acknowledgement}

This work was supported by the Major Program of National Science and Technology of China (135 Program, No. 2017YFB0309700).

\section{Conflict of Interest}

No conflict of interest.

\section{References}

1. KL Xie, JB Yu, DH Jiang (2007) Shade darkening effect of polyorganosiloxane modified with amino and hydroxyl groups on dyed polyester microfiber fabric. Journal of Applied Polymer Science 106(2): 1256-1262.

2. ML Zhao, XL Wang, JY Yu (2016) Preparation and characterization of poly (ethylene terephthalate) copolyesters and fibers modified with sodium-5-sulfo-bis-(hydroxyethyl)-isophthalate and poly (ethylene glycol). Journal of the Textile Institute 107(10): 1284-1295.

3. CN Hsiao, KS Huang (2005) Synthesis, characterization and applications of polyvinylpyrrolidone/SiO2 Hybrid Materials. Journal of Applied Polymer Science 96(5): 1936-1942.

4. WC Tsen, YC Shu, K Hsiao (2006) Preparation and physical properties of hollow polyester filaments with high breathability, water absorption and release rates. Polymers \& Polymer Composites 14: 107-118.

5. M Imran, BK Kim, M Han, BG Cho, DH Kim (2010) Sub- and supercritical glycolysis of polyethylene terephthalate (PET) into the monomer bis(2hydroxyethyl) terephthalate (BHET). Polymer Degradation and Stability 95(9): 1686-1693.

6. RQ Chen (2016) 60-Year Review for Disperse Dye (II). Dyestuff and Coloration 52: 18-30.

7. E Cleve, AK Gupta, U Denter, H Duffner, E Schollmeyer (1997) New mathematical model for determining time-dependent adsorption and diffusion of dyes into fibers through dye sorption curves in combination shades (part 1: mathematical fundamentals). Textile Research Journal 67: 701-706.

8. HS Park, IM Yang, JP Wu, MS Kim, HS Hahm, et al. (2001) Synthesis of silicone-acrylic resins and their applications to superweatherable coatings. Journal of Applied Polymer Science 81(7): 1614-1623.

9. KL Xie, AQ Hou, YQ Shi (2008) Synthesis of fluorine-containing acrylate copolymer and application as resins on dyed polyester microfiber fabric. Journal of Applied Polymer Science 108(3): 1778-1782.

10. YB Ren, W Zhou, P Zhang, YH Gu (2016) A deepening finishing agent and its preparation method. China Patent 201610193241.1.

11. T Kato, Y Saito (2001) Deepening agent for colored fiber and method for deepening color of fiber using the agent. Japan Patent 2001288683. 
12. S Arimoto (2002) Color deepening agent and method for color deepening processing. Japan Patent 2002285475.

13. DH Xie, ZH Gao, YX Jiang (2013) A copolymer emulsion as deepening agent for polyester fabric and its preparation method. China Patent 201210419746.7.

14. AQ Hou, YQ Shi (2009) Polymerization and surface-active properties of water-soluble amphiphilic polysiloxane copolymers modified with quaternary ammonium salts and long-carbon chain groupsmain. Materials Science and Engineering B-Advanced Functional Solid-State Materials 163: 99-104.

15. KL Xie, AQ Hou, YQ Shi, JB Yu (2007) The surface polymerising of fluoromonomer and the shade-darkening effect on dyed polyester microfibre fabric. Coloration Technology 123(5): 293-297.

16. T Lang (2008) Study on preparation and color-deepening property of corganosilane polyacrylate complex emulsion. PhD Thesis, Zhejiang University, China.

17. KM Zia, S Tabassum, S Barkaat-ul-Hasin, M Zuber, T Jamil, et al. (2011) Preparation of rich handles soft cellulosic fabric using amino siliconebased softener. Part-I: Surface smoothness and softness properties. International Journal of Biological Macromolecules 48(3): 482-487.

18. CB Yu, FF Wu, HT Dong, Y Nie, WT Zhu (2016) Cationic quaternary ammonium organic fluorosilicone deepening finishing agent, its preparation method and application. China Patent 201610345508.4.

19. M Morto, MA Deisz, EE Bostick (1964) Anionic polymerization of octamethycyclotetrasiloxane in tetrahydrofuran solution. Journal of Polymer Science 2(2): 513-522.

20. WT Grubb, RC Osthoff (2001) The Kinetics of polymerization of Octamethylcyclotetrasiloxane in miniemulsion II. Polymer 42: 72397246.

21. Y Chen, H Zhao, HY Shi (2009) Synthesis and properties of quaternary ammonium water-borne epoxy resin surfactants. Chemical Reagents 31(11): 915-918.

22. F D (2012) A specific distribution and bonding mechanism of emulsified adhesives in granular and fibrous substrates. Journal of Adhesion Science and Technology 9(7): 873-888.

23. CB Yu, FF Wu, HT Dong, WT Zhu (2016) Epoxy-based organic fluorosilicone oil emulsion darkening finishing agent and preparation method. China Patent 201610813723.2.

24. CB Yu, FF Wu, Y Nie, WT Zhu (2016) Modified amino organic fluorosilicone oil emulsion color-deepening finishing agent and preparation method. China Patent 201610813732.1.

25. C Ping, SP Liu, DZ Wang (2011) Epoxy resin and its application. $1^{\text {st }}$ ed. Beijing: Cheimical industry press: 23.

26. A Bismarck, G Pfeifer, J Springer (2012) Study on surface- and mechanical fiber characteristics and their effect on epoxy composite properties tuned by continuous anodic carbon fiber oxidation. Journal of Adhesion Science and Technology 14(5): 661-690.
27. LP He, WJ Li, DC Chen, JM Yuan, G Lu, et al. (2018) Microscopic mechanism of amino silicone oil modification and modification effect with different amino group contents based on molecular dynamics simulation. Applied Surface Science 440: 331-340.

28. LP He, WJ Li, DC Chen, DW Zhou, G Lu, et al. (2015) Effects of amino silicone oil modification on properties of ramie fiber and ramie fiber/ polypropylene composites. Materials \& Design 77: 142-148.

29. T Masuko (2005) Morphological and rheological behavior of poly(esterimide-siloxane) containing long chain alkyl groups/epoxy resin composites. Kobunshi Ronbunshu 62(2): 55-63.

30. A Bereck, D Riegel, A MATZAT (2001) Silicones on fibrous substrates: their mode of action. AATCC Review 1: 45-49.

31. MC Burrell, MD Butts, D Derr, S Genouvese RJ Perry (2004) Angledependent XPS study of functional group orientation for aminosilicone polymers adsorbed onto cellulose surfaces. Applied Surface Science 227(1-4): 1-6.

32. YJ Xu, H Yin, SF Yuan, ZR Chen (2009) Film morphology and orientation of amino silicone adsorbed onto cellulose substrate. Applied Surface Science 255(20): 8435-8442.

33. LL Wang, SS Cui, HG Ni, MH Wu, W Wang (2018) New washing-free printing binder based on organosilicon-modified polyacrylate for polyester fabric printing of disperse dyes. Progress in Organic Coatings 123:75-81

34. P Harbereder, A Bereck (2002) Silicone softeners. Review of Progress in Coloration and Related Topics 32(1): 125-137.

35. AK Samanta, DP Chattopadhyay, A Konar, DN Sharma (2003) Selective chemical pretreatments and post-treatments on microdenier polyester fabric for improving surface depth of colour. Indian Journal of Fibre \& Textile Research 28(1): 76-85.

36. ZZ Xu, ZF Zhu, W Li, CH Zhang (2017) Amphiphilic starch with 3-(trimethylammonium chloride)-2-hydroxypropyl and octenylsuccinyl substituents for strong adhesion to fibers. Journal of Adhesion Science and Technology 32(6): 609-624.

37. AQ Hou, MG Zhou, XJ Wang (2009) Modifying Cellulose with the Emulsion of the Triazine Derivative Containing the Tertiary Amino Group to Improve the Reactivity with Reactive Dyes. Journal of Dispersion Science and Technology 30(5): 643-648.

38. ZF Zhu, L Yan (2014) Effect of chain length of the alkyl in quaternary ammonium substituents on the adhesion-to-fiber, aerobic biodegradation, and desizability of quaternized cornstarch. Journal of Adhesion Science and Technology 29(2): 116-132.

39. KL Xie, Y Sun, AQ Hou (2006) Dyeing properties of net-modified cotton fabric with triazine derivative containing the multireactive and multicationic groups. Journal of Applied Polymer Science 100(6): 43884392.

40. ZL Fan, Q Li, XB Cai, ZB Li (2016) Synthesis of reactive waterborne polyurethane modified with quaternary ammonium chain extender and its color fixation properties. Journal of the Textile Institute 108(7): 1227-1233. 